\title{
Sucessão de lideranças em enfermagem: pensar e agir hoje para garantir o amanhã
}

\author{
Denize Bouttelet Munari ${ }^{1}$, Ana Lúcia Queiroz Bezerra ${ }^{2}$, Alyne Leite Nogueira ${ }^{3}$, \\ Bárbara Souza Rocha ${ }^{4}$, Elyana Teixeira Sousa ${ }^{5}$, Luana Cássia Miranda Ribeiro ${ }^{6}$
}

\footnotetext{
${ }^{1}$ Enfermeira, Doutora em Enfermagem. Professora Aposentada da Faculdade de Enfermagem da Universidade Federal de Goiás. Goiânia, GO, Brasil. E-mail: boutteletmunari@gmail.com.

${ }^{2}$ Enfermeira, Doutora em Enfermagem. Professora Adjunto da Faculdade de Enfermagem da Universidade Federal de Goiás. Goiânia, GO, Brasil. E-mail: aqueiroz.fen@gmail.com.

${ }^{3}$ Enfermeira, Mestre em Enfermagem. Discente do Programa de Pós-graduação em Enfermagem - nível - Doutorado da Faculdade de Enfermagem da Universidade Federal de Goiás. Goiânia, GO, Brasil. Email: alynenogueira@hotmail.com.

${ }^{4}$ Enfermeira, Doutora em Enfermagem. Professora Adjunto da Faculdade de Enfermagem da Universidade Federal de Goiás. Goiânia, GO, Brasil. E-mail: barbarasrocha@gmail.com.

${ }^{5}$ Discente do Programa de Pós-graduação em Enfermagem - nível - Doutorado da Faculdade de Enfermagem da Universidade Federal de Goiás. Goiânia, GO, Brasil. Email: elyanasousa@hotmail.com.

${ }^{6}$ Enfermeira, Doutora em Enfermagem. Docente do Instituto Federal de Goiás. Goiânia, GO, Brasil. E-mail: luaufg@yahoo.com.br.
}

\section{Como citar esse artigo:}

Munari DB, Bezerra ALQ, Nogueira AL, Rocha BS, Sousa ET, Ribeiro LCM. Sucessão de lideranças em enfermagem: pensar e agir hoje para garantir o amanhã. Rev. Eletr. Enf. [Internet]. 2017 [acesso em: ____19:a00. Disponível em: http://dx.doi.org/10.5216/ree.v19.46101.
O mundo experimenta uma crise de lideranças que tem evoluído com o envelhecimento de uma geração que foi pioneira em inovação e transformação da vida coletiva ${ }^{(1)}$. Mudanças têm sido observadas com a presença de novas gerações, que com novos hábitos, valores e comportamentos estão assumindo a gestão de organizações ou na linha de frente dessas. No entanto, nenhuma mudança pode ser realizada apenas com o novo, as gerações anteriores continuam sendo fundamentais para qualquer organização ${ }^{(2)}$.

Em algumas áreas, realmente é necessário profissionais com perfil de mais agilidade, mas por outro lado é importante que o conhecimento e a experiência dos outros profissionais sejam valorizadas, uma vez que estas características, diante de tantas mudanças, também auxiliam no desenvolvimento das organizações ${ }^{(3-4)}$. Nesse processo, a convivência nem sempre é harmoniosa, mas necessária para que as boas práticas de liderança sejam repassadas entre as gerações em benefício do bem comum $^{(1)}$. O ideal é que os líderes das organizações atuem com inteligência emocional e saibam gerir bem a convivência de ambos, assim como se preocupem com a ética e a relação profissional ${ }^{(5-6)}$.

Na concepção de Peter Drucker ${ }^{(7)}$ o "líder é alguém capaz de fazer com que os outros o sigam, sendo principalmente esta o tipo de habilidade que melhor o descreve. O líder eficaz não é alguém que se adore ou se admire. A qualidade da liderança não se mede pela popularidade que gozam, mas pelos resultados que ele consegue produzir. Os líderes estão em grande evidência. É por isso que lideram pelo exemplo. A liderança não é uma questão de classificação, de privilégios, de títulos ou de dinheiro. É uma 
questão de responsabilidade". Para esse autor, o preparo para a liderança, o compartilhamento de experiências e a preocupação com a sucessão e formação de novos líderes é fundamental para o sucesso de qualquer organização ${ }^{(7)}$.

$\mathrm{Na}$ enfermagem essa mudança vem ocorrendo de forma rápida e exige que as atuais lideranças se comprometam com o desenvolvimento da profissão, preparando e facilitando a troca de experiências entre as gerações de modo a planejar e garantir um futuro promissor para a carreira ${ }^{(1,8-9)}$.

O aumento da idade da força de trabalho ${ }^{(8,10-13)}$, a iminente aposentadoria de grande número de enfermeiros nos próximos anos ${ }^{(11-12,14)}$ associado ao fato de que, jovens enfermeiros demonstram pouco interesse em posições de liderança e ainda a falta de investimentos na formação profissional e no aprimoramento do desempenho na liderança ${ }^{(15)}$ são aspectos que anunciam uma crise sem precedentes na enfermagem mundial ${ }^{(13,16)}$.

Essa crise tende a deixar os futuros líderes de enfermagem alienados e mal preparados para a função predizendo um impacto nos serviços de modo geral, desde as instituições de saúde até as universidades e centros de formação e pesquisa, onde os docentes/pesquisadores passam pelo mesmo processo de aposentadoria $^{(17)}$. Uma das possibilidades de se atenuar a situação é a realização de projetos que estimulem o compartilhamento de experiências entre profissionais de diferentes gerações, garantindo a sucessão de lideranças na enfermagem ${ }^{(8,17)}$.

Embora este seja um assunto da mais alta relevância, o processo de sucessão de lideranças não tem tido a atenção que merece, haja vista a limitada produção científica acerca do tema, o pouco investimento nas instituições de saúde e de educação em direção ao preparo de lideranças para o futuro, tampouco esse é um tema tratado como pauta em programas de educação permanente ${ }^{(9,11,17)}$.

Ao recorrermos a literatura sobre a temática em uma revisão não sistematizada observamos que se trata de tema inovador, mas incipiente inclusive em países desenvolvidos. Os resultados da pesquisa apontaram que existem artigos teóricos conceituais acerca do processo de sucessão de lideranças em enfermagem, porém poucas pesquisas mostram experiências de implantação e acompanhamento de processos sucessórios (PS), embora é consenso nos estudos a importância do tema para o futuro da profissão.

A finalidade do PS é garantir continuidade da liderança nas instituições por meio do desenvolvimento e avaliação de indivíduos com potencial para ocupar futuras posições de comando ${ }^{(11,13)}$. O PS é complexo e integra elementos como o planejamento estratégico, alocação de recursos, posição-chave a ser substituída/identificação de competências, seleção de líderes potenciais, desenvolvimento de liderança, mentoring/coaching e avaliação de candidatos ${ }^{(18-19)}$.

Estudos mostraram que o PS facilita a transição de líderes, diminui o estresse nas equipes, melhora a retenção e recrutamento de enfermeiros com alto potencial ${ }^{(8,14,18)}$, reduz taxas de rotatividade de gerentes de enfermagem ${ }^{(8,13)}$, diminui os custos de substituição ${ }^{(13-14,18,20)}$, mantêm níveis de produtividade ${ }^{(18-19)}$, melhora o ambiente de trabalho ${ }^{(8-13)}$ e aumenta a satisfação do cliente e dos profissionais ${ }^{(9)}$.

O desenvolvimento de novas competências para liderança cria uma cultura que suporta a progressão 
de carreira, o que demonstra compromisso com o desenvolvimento da profissão ${ }^{(18)}$. O PS garante padrões de qualidade na assistência em saúde e a preservação do conhecimento produzido pelas diversas gerações de enfermeiros.

A partir da implantação do PS percebe-se o fortalecimento da gerência e liderança, dando continuidade a experiências de líderes mais experientes, que auxiliam na seleção, preparação e retenção de novos talentos. Esse processo também facilita o convencimento dos mais jovens em relação a importância de se tornarem líderes ${ }^{(13,21)}$.

Diante dessa realidade, para se protagonizar um futuro melhor para a enfermagem, é fundamental que haja preocupação e ocupação quanto a importante tarefa de desenvolver novas lideranças, sobretudo, possibilitando que as diversas gerações de enfermeiros sejam capazes de conviver em uma relação de respeito nos diferentes contextos de atuação.

Para se ter sucesso na árdua tarefa de desenvolver um processo sucessório, é necessário uma relação mútua e respeitosa entre as gerações, de forma a oportunizar aos mais velhos, espaço para contarem suas histórias e oferecerem seus conselhos e, aos mais jovens, o compartilhamento de seus sonhos, dificuldades e desafios. Que ambos sejam capazes de trocar experiências, conhecimentos e vivências, planejando um futuro para a nossa profissão que atenda as diversas expectativas.

O trabalho de um líder mais jovem pode ser bem feito e trazer bons resultados, porém é necessário que ele aceite os ensinamentos do profissional mais experiente, e que também se empenhe em passar a ele suas habilidades mais relevantes. Nesse contexto, cabe às organizações direcionar seus objetivos e o trabalho de seus profissionais, além de utilizar todas as ferramentas e habilidades que essa geração oferece para desenvolver o melhor trabalho possível. Esse pode ser um caminho para o alcance da formação de líderes eficazes pautados por comportamentos éticos e decisões inovadoras.

Nesse editorial nos propusemos, além de trazer as ideias, apresentar na prática o que pode se resultar da convivência de diferentes gerações em busca do desenvolvimento da enfermagem e de seu crescimento. Ele foi escrito por docentes já em processo de aposentadoria preocupadas com o futuro da profissão e por suas jovens seguidoras que aliam a experiência dos mestres, aos sonhos do futuro de suas carreiras.

Que esse texto seja convincente, o suficiente, para instigar líderes atuais, professores e pesquisadores sênior a se responsabilizar da importante missão de formar novas gerações, compartilhando saberes e experiências, promovendo a extensão do seu trabalho na vida de outros enfermeiros, deixando assim o seu importante legado na história.

\section{REFERÊNCIAS}

1. Munari DB, Bezerra ALQ, Chaves LDP, Rocha BS, Ribeiro LCM. Importância da formação e desafios para o desenvolvimento de lideranças em enfermagem. In: Associação Brasileira de Enfermagem; Vale EG, Peruzzo SA, Felli VEA, organizadores. PROENF Programa de Atualização em Enfermagem: Gestão: Ciclo 5. Porto Alegre: Artmed Panamericana; 2015. p. 9-42.

2. Robinson-Walker C. Succession planning: moving the dial from "should" to "must". Nurs Adm Q [Internet]. 2013 
[acesso em: 27 mar. 2017];37(1):37-43. Disponível em: http://dx.doi.org/10.1097/NAQ.0b013e3182751622.

3. Fischer SA. Transformational leadership in nursing: a concept analysis. J Adv Nurs [Internet]. 2016 [acesso em: 27 mar. 2017];72(11):2644-53. Disponível em: http://dx.doi.org/10.1111/jan.13049.

4. Carney, M. Leadership in nursing: current and future perspectives and challenges. J Nurs Manag [Internet]. 2009 [acesso em: 27 mar. 2017];17(4):411-4. Disponível em: http://dx.doi.org/10.1111/j.1365-2834.2009.01024.x.

5. Johnson-Dennis N. Building succession planning into nursing culture. Nurs Manage [Internet]. 2014 [acesso em: 27 mar. 2017];45(7):8. Disponível em: http://dx.doi.org/10.1097/01.NUMA.0000451040.99834.e0.

6. Coughlin C, Hogan P. Succession planning: after you, then who? Nurs Manage [Internet]. 2008 [acesso em: 27 mar. 2017];39(11):40-6. Disponível em: http://dx.doi.org/10.1097/01.NUMA.0000340818.06024.3e.

7. Drucker P F. Desafios gerenciais para o século XXI. São Paulo; Pioneira, 2001.

8. Nelsey L, Brownie S. Effective leadership, teamwork and mentoring - Essential elements in promoting generational cohesion in the nursing workforce and retaining nurses. Collegian [Internet]. 2012 [acesso em: 27 mar.

2017];19(4):197-202. Disponível em: https://www.clinicalkey.com/nursing/\#!/content/playContent/1-s2.0-

S1322769612000303.

9. Titzer J, Phillips T, Tooley S, Hall N, Shirey M. Nurse manager succession planning: synthesis of the evidence. J Nurs Manag [Internet]. 2013 [acesso em: 27 mar. 2017];21(7):971-9. Disponível em:

http://dx.doi.org/10.1111/jonm.12179.

KT, DeLucas C. Succession planning: using simulation to develop nurse leaders for the future. Nurse Leader [Internet]. 2014 [acesso em: 27 mar. 2017];12(5):24-8. Disponível em: http://dx.doi.org/10.1016/j.mnl.2014.07.009.

11. McCallin A, Bamford-Wade A, Frankson C. Leadership Succession Planning: A Key Issue for the Nursing Profession. Nurse Leader [Internet]. 2009 [acesso em: 27 mar. 2017];7(6):40-4. Disponível em:

http://dx.doi.org/10.1016/j.mnl.2009.07.008.

12. Watson CA, Houlahan B. CNO succession planning: a case study. Nurse Leader [Internet]. 2009 [acesso em: 27 mar. 2017];7(4):25-9. Disponível em: http://dx.doi.org/10.1016/j.mnl.2009.05.012.

13. Titzer JL, Shirey MR. Nurse manager succession planning: a concept analysis. Nursing Forum [Internet]. 2013 [acesso em: 27 mar. 2017];48(3):155-64. Disponível em: http://dx.doi.org/10.1111/nuf.12024.

14. Moore LW, Sublett C, Leahy C. Nurse managers' insights regarding their role highlight the need for practice changes. Appl Nurs Res [Internet]. 2016 [acesso em: 27 mar. 2017];30:98-103. Disponível em:

http://dx.doi.org/10.1016/j.apnr.2015.11.006.

15. O'Neil E, Morjikian RL, Cherner D, Hirschkorn C, West T. Developing nursing leaders: an overview of trends and programs. J Nurs Adm [Internet]. 2008 [acesso em: 27 mar. 2017];38(4):178-83. Disponível em:

http://dx.doi.org/10.1097/01.NNA.0000312754.61170.fa.

16. Stichler J. Succession planning: why grooming their replacements is critical for nurse leaders. Nurs Womens Health [Internet]. 2008 [acesso em: 27 mar. 2017];12(6):525-8. Disponível em: http://dx.doi.org/10.1111/j.1751486X.2008.00387.x.

17. Vogelsang LE. Early succession planning for nursing faculty. Nurse Educ Today [Internet]. 2014 [acesso em: 27 mar. 2017];34(10):1277-9. Disponível em: http://dx.doi.org/10.1016/j.nedt.2014.05.015.

18. Bolton J, Roy W. Succession planning: securing the future. J Nurs Adm [Internet]. 2004 [acesso em: 27 mar. 2017];34(12):589-93. Disponível em:

http://journals.Iww.com/jonajournal/Abstract/2004/12000/Succession_Planning_Securing_the_Future.9.aspx.

19. Carriere BK, Muise M, Cummings G, Newburn-Cook C. Healthcare succession planning: an integrative review. J Nurs Adm [Internet]. 2009 [acesso em: 27 mar. 2017];39(12):548-55. Disponível em:

http://dx.doi.org/10.1097/NNA.0b013e3181c18010.

20. Redman RW. Leadership succession planning: an evidence-based approach for managing the future. J Nurs Adm [Internet]. 2006 [acesso em: 27 mar. 2017];36(6):292-7. Disponível em:

http://journals.Iww.com/jonajournal/pages/articleviewer.aspx?year=2006\&issue=06000\&article=00003\&type=abstra ct.

21. Scully NJ. Leadership in nursing: The importance of recognising inherent values and attributes to secure a positive future for the profession. Collegian [Internet]. 2015 [acesso em: 27 mar. 2017];22(4):439-44. Disponível em:

http://dx.doi.org/10.1016/j.colegn.2014.09.004. 